\title{
Mechanisms by which the Inclusion of Natural Fibres Enhance the Properties of Soil Blocks for Construction
}

\section{Humphrey Danso, Brett Martinson, Muhammad Ali, John Williams}

\begin{abstract}
Soil blocks are widely used for construction, especially in less economically developed countries. Addition of agricultural waste fibres has been shown to improve the properties of these blocks, however unlike most composites the fibres are not bound to the soil matrix. Therefore the reinforcement mechanisms are different and not well characterised. This paper investigates these mechanisms through a series of experimental studies to inform the development of better guidance for practitioners, and hence improve housing for low-income communities. The microstructural characteristics were investigated using SEM, CT scan, optical microscope analysis and pull out testing. It was established that fibres in the soil matrix are randomly distributed with gaps between the fibres and soil matrix due to fibre shrinkage during drying of the blocks. It was also found that natural fibres in soil matrix can either be pulled-out or rupture under load depending on the depth of fibres embedment in the soil matrix.
\end{abstract}

Keywords: Natural fibres; CT analysis; Optical microscopy; Scanning electron microscopy; Soil blocks; Pull-out test 


\section{Introduction}

The technique of using fibres to improve or enhance the strength properties of soil blocks is widely used in the field of construction and building materials. This practice is not new as the ancient civilisations have used straw and hay to reinforce mud blocks for centuries in order to increase their strength properties for building construction purposes. Natural fibre-soil composite has the advantage of providing houses with low embodied energy, minimal impact on the environment and the ability to provide better occupant comfort.

Fibre reinforced soil composite is defined as a soil mass that contains randomly distributed, discrete elements (fibres) that provide an improvement in the mechanical performance of the fibre-soil composite ${ }^{32}$. The performance of the fibre reinforced soil matrix is dependent on factors such as fibre type, particle size distribution of soil, aspect ratio of fibres, fraction of fibre to soil and fibre characteristics. Natural fibres can be used as reinforcement in eco-friendly composites suitable for the building industry as reinforcing materials in order to improve the engineering properties of different types of soil $^{38,41}$.

This study scientifically investigates the microstructure and mechanisms of this novel composite material i.e. compacted soil blocks reinforced with natural fibres to inform the development of better guidance for practitioners. This material is distinct from many other composites due to the heterogeneous nature of the soil matrix resulting in more complex behaviour than is normally found in homogeneous matrices such as concrete or polymers. The interaction between fibre and soil matrix is further complicated by the addition of water with each component differing in expansion resulting in relative dimensional changes upon drying and subsequent debonding.

Lately, there has been increased research interest in soil matrices reinforced with natural fibres, due to the fact that they are renewable, biodegradable, environmentally friendly 
and low-cost. It has been demonstrated that fibres can be considered as good earth reinforcement material ${ }^{46}$. A number of studies also showed improvement in properties of fibre reinforced soil blocks over the unreinforced blocks 1-3, 5, 10, 11, 14, 15, 22-24, 28-31, 36, 39, 43 . However, there is limited information on the microstructure and mechanisms of how the fibre-soil matrix affect the strength properties.

While widely used informally, at present, the technology of fibre reinforcement of soils has not been decisively adopted by the formal building sector mainly because of the lack of methodical performance appraisal, which requires the understanding of the interaction between the soil and the fibre ${ }^{21}$. The benefit of fibre reinforcement comes from fibre-soil interaction, and insight into the internal mechanism of the interaction between fibre and soil is therefore of importance to improve design processes and for wider acceptance of the material in the formal construction industry. This study therefore investigates the mechanisms by which a compacted soil matrix is reinforced with natural fibres, to determine the distribution of the fibres in matrix, any existence of gaps at the interface of the fibres with the matrix and the fibre pull-out from the matrix. The research presented in this paper is part of a larger research effort aimed at developing fibre reinforced soil blocks for low-cost housing in less economically developed countries (LEDCs). Some of

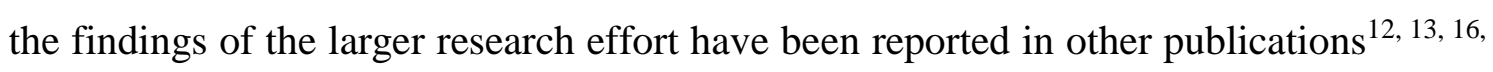
18,20 .

\section{Experimental Materials and Methods}

To characterise the mechanisms by which fibres enhance the properties of soil blocks it is necessary to understand (1) the distribution of fibres, (2) the nature of the interface between the fibres and soil matrix, and (3) the pull-out characteristics of the fibres embedded in the soil matrix. To assess the distribution of fibres, computerised tomography (CT) scanning was used. To investigate the nature of the interface between 
the fibres and soil matrix, optical microscopy and SEM were used. The pull-out was measured directly by mechanically testing the resistance of single fibres embedded in a soil specimen.

\subsection{Materials}

The main materials used for the experiment were soil, agricultural waste fibres (sugarcane bagasse, coconut and oil palm) and water. The soil sample was obtained from Horsea Island, Portsmouth, UK. Properties of the soil are reported in Table 1, and the particle size distribution curve is shown in Fig. 1. The soil has a liquid limit of $18 \%$ and a plasticity index of $13.7 \%$ and hence could be classified as low plasticity clay soil (CL) according to BS1377:2 ${ }^{6}$. The optimum moisture content (OMC) for the soil without stabilisation was obtained by using a Standard Proctor test ${ }^{7}$ and was $11.8 \%$, the maximum dry density (MDD) was $1.83 \mathrm{Mg} / \mathrm{m}^{3}$. The $\mathrm{pH}$ of the soil was 6.67 which is close to neutral. Chemical element/composition of the soil was determined through inductively coupled plasma mass spectrometry (ICP-MS) analysis method in accordance with BS EN ISO 1729:4 ${ }^{8}$ and the result is presented in Table 2.

Coconut, sugarcane bagasse and oil palm fruit fibres obtained from Ghana were used as reinforcing materials in the soil blocks. These fibres have been selected as they cover a wide range of properties, and are also abundant agricultural waste materials in West Africa. The images of each fibre type are shown in Fig. 2. SEM images of single fibre were determined with JSM-6100 scanning microscope at 35× magnification for each fibre type to show the texture of the fibres. The bagasse fibre appears to be very rough in texture as compared to coconut and oil palm fibres. The difference between dry and wet fibres' diameter were determined using computerised optical microscope (OLYMPUS BX40) with Leica Application Suite version 3.4.0. More information on the preparation of these fibres can be found in the study by Danso et al. ${ }^{17}$. The properties of the fibres such as 
diameter, tensile strength, modulus of elasticity and water absorption are presented in Table 3.

\subsection{Specimen preparation}

Fibres were added at $1.0 \%$ by weight of soil as recommended by previous studies 37,47 and $11.8 \%$ water (as obtained by OMC) was used for making the specimen. The soil was first spread on a platform, the fibres were then spread on the soil and turned over and over until a uniform mixture was obtained. Water was sprinkled on the soil-fibre mixture and turned over and again to obtain a homogenous mixture. Cylindrical specimens of $80 \mathrm{~mm}$ length $\times 40 \mathrm{~mm}$ diameter (Fig. 3) were prepared by placing $200 \mathrm{~g}$ of the mixture into a cylindrical mould with $40 \mathrm{~mm}$ internal diameter and $125 \mathrm{~mm}$ length and quasi-statically compressing at $10 \mathrm{MPa}$ pressure, using a close fitting piston with a Tinius Olsen H50KS resulting in a length of about $80 \mathrm{~mm}$. These specimens were used to find out the distribution of the fibres in the soil matrix. $50 \mathrm{~mm}$ cube specimens (Fig. 3) were prepared with a steel mould with internal dimension $50 \times 50 \times 50 \mathrm{~mm}$ and compressed at $10 \mathrm{MPa}$ pressure with a Tinius Olsen H50KS. One mould was placed on the other which allowed the mixture to be placed inside and compressed to $50 \mathrm{~mm}$ with a wooden plate on top. The cubes were used to determine the gaps between the fibres and the soil matrix. All the specimens were dried in fan assisted Genlab electronic oven at a temperature of $40{ }^{\circ} \mathrm{C}$ for five days when the mass had stabilised.

Soil block specimens of $20 \times 20 \times 60 \mathrm{~mm}$ were prepared with single fibre embedded in each sample for the pull-out test. Four different fibre lengths representing 1/2, 1/4, 1/8 and $1 / 16$ of the total length of each fibre were embedded in the soil matrix leaving the remaining length out of the specimen. Details of the fibre length and diameter are presented in Table 4. 
The specimen were made with a steel mould and a press with $1 \mathrm{~mm}$ hole drilled in the middle to keep the fibre outside the soil and then pressed with Tinius Olsen H50KS at $10 \mathrm{MPa}$ pressure. The specimen were then pushed out of the mould and allowed to air dry (Fig. 4) for three weeks when the mass stabilised.

\subsection{Testing methods}

\subsubsection{Fibre distribution in soil matrix}

A computerised tomography (CT) scan analysis was conducted to investigate the distribution of the fibres in the soil matrix. A Metric XT H 225 Microfocus CT Scanner was used to scan the cylinder specimens. The CT scan produced images (slices) which were modelled with VGStudio MAX version 2.0 to produce 3D and 2D images of the cylinder specimen showing the orientation of the fibres.

\subsubsection{Gaps between fibre and soil matrix}

Scanning electron microscopy (SEM) and optical microscope analysis were conducted to investigate the soil-fibre interface at the periphery of the specimen. Selected cubes from each fibre type were broken to expose the internal parts for the analysis with a JSM-6100 scanning microscope and a computerised optical microscope (OLYMPUS BX40) with Leica Application Suite version 3.4.0 (Fig. 5). Each specimen was placed in the JSM6100 scanning microscope at 100x magnification which revealed gaps at the edge of the fibres in the soil matrix. Each specimen was also placed in the optical microscope. With the help of the Leica Application Suite installed on the computer, the gaps were measured and recorded.

\subsubsection{Pull-out test}

The pull-out test was conducted to ascertain if the fibres in the soil matrix pull-out or rupture when load is applied on the reinforced soil bocks. A single-fibre pull-out test was carried out following the method used in previous studies on steel fibres in cement 
composite $^{4,45}$. The specimens were subjected to pull-out using a Tinius Olsen H50KS as shown in Fig. 6. The test specimen was fixed to the bottom jaw of the test machine while the free end of the fibre was held by the upper jaw. The matrix remained rigid while, the fibre-held upper jaw moved upward with a rate of $1 \mathrm{~mm} / \mathrm{min}$ until fibre failed or pulledout.

\section{Results and Discussion}

\subsection{Fibre distribution in soil matrix}

The result obtained from the CT scan and modelling of the slices is shown in Fig. 7. The images obtained show the cylindrical specimen with the fibres distributed in it. The 3D view shows the fibres are general well distributed however the 2D slice shows some edge effects and alignment with the walls. This is probably an artefact of the preparation of the cylindrical specimen, where friction with the mould would be greater than a rectangular block mould. Overall the fibres in the soil matrix are generally well distributed. This agrees well with Diambra et al. ${ }^{21}$ who observed that the use of flexible fibres are usually randomly distributed throughout the soil mass when fibres are used in geotechnical applications. Studies by Ibraim et al. ${ }^{27}$ and Maeda and Ibraim ${ }^{35}$ found that randomly distributed flexible fibres generate a bond within the soil. This means the orientation of the fibres in the soil matrix have effect on the performance properties of the soil blocks. In the studies of fibre reinforced cement, Maalej et al. ${ }^{34}$ and Slosarczyk ${ }^{40}$ found that the use of randomly distributed fibres in a brittle matrix increase toughness, increase tensile strength, reduce shrinkage and provide good crack-width control. This means the even distribution of the fibres in the soil matrix can help to improve the strength properties in the soil blocks. 


\subsection{Gaps between fibre and soil matrix}

The images obtained from SEM analysis (with small broken samples) are shown in Fig. 8 and images from optical microscopy are shown in Fig. 9. They illustrate the inter-spatial relationship between fibres and the soil matrix of the enhanced soil blocks. Critical observations of the images show that there are gaps formed between the fibres and the soil matrix. Studies by Cao et al. ${ }^{9}$ on biodegradable aliphatic polyester composites reinforced with bagasse, Rivera-Gómez et al. ${ }^{38}$ on wool fibre in the soil and Zhu et al. ${ }^{48}$ on flax/epoxy composites obtained similar results. The extent of these gaps may be attributed to the disturbances during breakage of the specimen or differential shrinkage of the fibres and matrix during drying. The gaps sizes were measured and the mean and standard deviation values estimated from twenty measurements taken from each fibre type (Table 5).

The images and measurements indicate that gaps found between coconut fibres and the soil matrix are bigger than those between sugarcane bagasse and oil palm fibre reinforced blocks. The average gap out of twenty fibre-soil specimens of each fibre type showed that the coconut fibre-soil matrix had the largest gaps, the oil palm fibre-soil matrix gaps were approximately half of the size, and the bagasse fibre-soil matrix had gaps approximately a quarter of the size of the coconut fibre reinforced blocks.

To determine whether these gaps were caused by shrinking of the fibres or the soil matrix, twenty fibres from each fibre type were randomly selected and measured in dried state and wet state after immersing in water for $48 \mathrm{hrs}$. The results are also shown in Table 5 . The results show that the different fibres had different rates of shrinkage during drying. The rank order of gaps followed the rank order of shrinkage (coconut>palm oil >bagasse). This suggests the gaps found between the fibres and the soil matrix is largely caused by shrinking of the fibres from wet state to dry state. The differences in the radius of the dry 
and wet fibres were, however found to be larger than the gaps measured between fibres and the soil matrix.

This could be explained considering that, when the fibres are kept in water, they absorb moisture and therefore fully expand, and on the other hand when mixed with soil and compacted the fibres undergo shrinkage due to the applied pressure, and therefore have less shrinkage on drying in situ. This means that there are two stagesof fibre shrinkage; (1) shrinkage due to the compaction force when making the blocks, and (2) shrinkage due to drying of the blocks. As the first shrinkage is made in intimate contact with the soil, the gaps found in the optical microscope analysis represent the gaps created by the drying of the blocks (second shrinkage). It must be noted that these two shrinkage stages are all caused by loss of absorbed water in the fibres, which is the difference in dry and wet fibre diameter.

The fibre-soil matrix is generally affected by the dimensional changes of the fibres which can occur due to changes in moisture and temperature ${ }^{25}$. The changes in fibre dimension occur during the drying of the fibre-soil matrix which may result in a poor interfacial bond ${ }^{26}$. This behaviour of the fibres in the soil can weaken the bond between the fibres and the soil matrix ${ }^{25,26}$. If the gap between the composites is large, it contributes to making it easier for fibres to pull out from the soil matrix which results in adhesion failure ${ }^{33}$. To determine if gaps contribute to ease of pull out from the fibre reinforced soil matrix, pull out tests were conducted.

\subsection{Pull-out result}

The pull-out test results are reported in Table 6 as the number of fibres from 3 replicates which pulled out during the test, and those that did not pull out were tested to failure. It can be seen that all the three replicates of bagasse fibre-soil specimens pulled out with fibre lengths $7 \mathrm{~mm}$ embedded in the soil matrix, while oil palm pulled out at $3 \mathrm{~mm}$ lengths. 
With coconut fibres, two out of three replicates for $13 \mathrm{~mm}$ and all the three replicates for $6 \mathrm{~mm}$ pulled out of the soil matrix.

The results show that the fibres with low embedded length tended to pull out, whereas the fibres with high embedded lengths ruptured. Examples of fibres failure are presented in Fig. 10. It therefore means the critical pull out of fibre length lies between the values where they rupture and the values where they pull-out, thus $7-14,3-5$ and $13-26 \mathrm{~mm}$, respectively for bagasse, oil palm and coconut fibres. The highest fibre length pull out was seen from coconut, which has the highest tensile strength of the 3 fibres as demonstrated in a previous study ${ }^{19}$.

Studies by Danso et al. ${ }^{17,19}$ also demonstrated that the compressive strength of the coconut fibre reinforced soil blocks performed better than the bagasse and oil palm fibres reinforced soil blocks. The pull out for all the fibre lengths can be explained by fibres poor interfacial bond with the soil matrix and short lengths of the fibres implanted in the soil matrix. The results mean that with natural fibres in soil, the mechanism can either be pull-out or rupture of the fibres, whereas studies ${ }^{4,45}$ on steel fibres in cement composite the mechanism is almost always pull-out because steel fibres are designed that way. If they were long enough they would rupture.

\section{Conclusion}

This study investigated the mechanisms by which a compacted soil matrix is reinforced with natural fibres, to determine the distribution of the fibres in matrix, any existence of gaps at the peripheral of the fibres in the matrix and the fibres pull-out from the matrix. On the basis of the experimental results obtained, the following summary can be made:

- CT scan micrograph revealed that the fibres in the soil matrix are generally well distributed with some localised directionality observed near to the surface, likely caused by shearing as the soil is compacted. This implies that the fibres in the 
matrix have unsystematic orientation as compared to steel bars in reinforced concrete. This is however good to reduce cracking effect and also increase strength.

- SEM and optical microscope analysis found that gaps exist between the fibres and the soil matrix. Coconut fibres-soil matrix recorded the biggest gap while bagasse obtained the least gap between the fibres and the soil matrix. This relates to the ratio of different fibres shrinkage during drying, but in situ conditions (e.g. compaction) mean that this is not directly proportional to radial drying shrinkage seen in ex situ laboratory testing.

- Shrinkage was also found to consist of 2 stages, (1) shrinkage due to applied pressure during block formation and (2) shrinkage due to drying. It may, therefore be possible that by controlling the water content of the natural fibres to reduce expansion within the limits of shrinkage (1), and to eliminate the gaps between fibre and soil.

- Natural fibres in soil matrix can either be pull-out or rupture under failure force depending on the depth of fibres embedment in the soil matrix. This is contrarily to steel fibres in cement composite which almost always pull-out.

- Further work is required to establish the exact point of fibres pull-out, as the pullout found in this study was between two fibre lengths. The effect of fibre shrinkage under pressure and with different water content could also be investigated. These are important to fully understand the interactions between the fibres and the soil matrix as a composite material.

The paper therefore concludes that, though the fibres are randomly distributed in the soil matrix which has the potential of improving the engineering properties of the composite, the fibres are not well bonded with the soil matrix. This means the full benefit of the inclusion of natural fibres in the soil blocks may not be achieved even though studies have shown improvement of the properties of the blocks. Studies by Subrianto et al. ${ }^{42}$ 
and Tang et al. ${ }^{44}$ found that cement inclusion dramatically improved the interfacial bond between the fibres and the soil matrix. 


\section{Reference}

1 M Achenza, and L. Fenu, 'On Earth Stabilization with Natural Polymers for Earth Masonry Construction', Materials and Structures 39 (2006), 21-27, DOI 10.1617/s11527-005-9000-0.

2 F. Aymerich, L. Fenu, L. Francesconi, and P. Meloni, 'Fracture Behaviour of a Fibre Reinforced Earthen Material under Static and Impact Flexural Loading', Construction and Building Materials, 109 (2016), 109-19, http://dx.doi.org/10.1016/j.conbuildmat.2016.01.046.

3 F. Aymerich, L. Fenu, and P. Meloni, 'Effect of Reinforcing Wool fibres on Fracture and Energy Absorption Properties of an Earthen Material', Construction and Building Materials 27 (2012), 66-72, doi:10.1016/j.conbuildmat.2011.08.008.

4 A. Beglarigale, and H. Yazıcı, 'Pull-out Behavior of Steel Fiber Embedded in Flowable Rpc and Ordinary Mortar', Construction and Building Materials, 75 (2015), 255-65; doi:10.1016/j.conbuildmat.2014.11.037

5 H. Binici, O. Aksogan, and T. Shah, 'Investigation of fibre Reinforced Mud Brick as a Building Material', Construction and Building Materials, 19 (2005), 313-18, doi:10.1016/j.conbuildmat.2004.07.013.

6 BS1377, 'Methods of Test for Soil for Civil Engineering Purposes', in Part 2: classification tests (British Standards, 1990).

7 BS 1377 Part 4, 'Methods of Test for Soils for Civil Engineering Purpose', in Methods of test for soils for civil engineering purpose ( British Standards, 1990).

8 BS EN ISO 17294 Part 1, 'Water Quality. Application of Inductively Coupled Plasma Mass Spectrometry (Icp-Ms)', in Water quality. Application of inductively coupled plasma mass spectrometry (ICP-MS) (British Standards, 2006).

9 Y. Cao, S. Shibata, and I. Fukumoto, 'Mechanical Properties of Biodegradable Composites Reinforced with Bagasse Fibre before and after Alkali Treatments', Composites Part A: Applied Science and Manufacturing, 37 (2006), 423-29, doi:10.1016/j.compositesa.2005.05.045.

10 C. M. Chan, 'Effect of Natural Fibers Inclusion in Clay Bricks: Physico-Mechanical Properties', International Journal of Civil and Environmental Engineering, 3 (2011), 51-57.

$11 \mathrm{H}$. Danso, 'Use of Agricultural Waste Fibres as Enhancement of Soil Blocks for Low-Cost Housing in Ghana' (University of Portsmouth, http://eprints.port.ac.uk/id/eprint/20762, 2015).

12 H. Danso, 'Influence of Compacting Rate on the Properties of Compressed Earth Blocks', Advances in Materials Science and Engineering 2016 (2016), 1-8, http://dx.doi.org/10.1155/2016/8780368.

13 H. Danso, B. Martinson, M. Ali, and C. Mant, 'Performance Characteristics of Enhanced Soil Blocks: A Quantitative Review', Building Research \& Information, 43 (2015), 253-62. DOI: 10.1080/09613218.2014.933293.

14 H. Danso, B. Martinson, M. Ali, and C. Mant, 'Performance Characteristics of Enhanced Soil Blocks: A Quantitative Review', Building Research and Information, 43 (2015), 253-62. DOI: 10.1080/09613218.2014.933293.

15 H. Danso, B. Martinson, M. Ali, and J. B. Williams, ' Effect of Sugarcane Bagasse Fibre on the Strength Properties of Soil Blocks', in 1st International Conference on Bio-based Building Materials (June 22-24, Clermont-Ferrand, France: 2015), pp. 251-56.

16 H. Danso, D. B. Martinson, M. Ali, and J. William, 'Effect of Fibre Aspect Ratio on Mechanical Properties of Soil Building Blocks', Construction and Building Materials, 83 (2015), 314-19, doi:10.1016/j.conbuildmat.2015.03.039. 
17 H. Danso, D. B. Martinson, M. Ali, and J. Williams, 'Effect of Fibre Aspect Ratio on Mechanical Properties of Soil Building Blocks', Construction and Building Materials, 83 (2015), 314-19, doi:10.1016/j.conbuildmat.2015.03.039.

18 H. Danso, D. B. Martinson, M. Ali, and J. Williams, 'Effect of Sugarcane Bagasse Fibre on the Strength Properties of Soil Blocks ', in 1st International Conference on Bio-based Building Materials (June 22-24, Clermont-Ferrand, France: 2015).

19 H. Danso, D. B. Martinson, M. Ali, and J. B. Williams, 'Physical, Mechanical and Durability Properties of Soil Building Blocks Reinforced with Natural Fibres', Construction and Building Materials 101 (2015), 797-809, http://dx.doi.org/10.1016/j.conbuildmat.2015.10.069.

20 H. Danso, D.B. Martinson, M. Ali, and J.B. Williams, 'Physical, Mechanical and Durability Properties of Soil Building Blocks Reinforced with Natural Fibres', Construction and Building Materials, 101 (2015), 797-809, http://dx.doi.org/10.1016/j.conbuildmat.2015.10.069.

21 A. Diambra, E. Ibraim, A. R. Russell, and D. Muir Wood, 'Fibre Reinforced Sands: From Experiments to Modelling and Beyond', International Journal for Numerical and Analytical Methods in Geomechanics, 37 (2013), 2427-55, DOI: 10.1002/nag.2142.

22 P. Donkor, and E. Obonyo, 'Earthen Construction Materials: Assessing the Feasibility of Improving Strength and Deformability of Compressed Earth Blocks Using Polypropylene Fibers', Materials \& Design, 83 (2015), 813-19, http://dx.doi.org/10.1016/i.matdes.2015.06.017.

23 P. Donkor, and E. Obonyo, 'Compressed Soil Blocks: Influence of Fibers on Flexural Properties and Failure Mechanism', Construction and Building Materials, 121 (2016), 25-33, doi:10.1016/j.conbuildmat.2016.05.151.

24 C. Galán-Marín, C. Rivera-Gómez, and J. Petric, 'Clay-Based Composite Stabilised with Natural Polymer and Fibre', Construction and Building Materials, 20 (2010), 1462-68, doi:10.016/j.conbuildmat.2010.01.008.

25 K. Ghavami, R. D. T. Filho, and N. P. Barbosac, 'Behaviour of Composite Soil Reinforced with Natural Fibres', Cement and Concrete Composites, 21 (1999), 39-48.

26 S M Hejazi, M Sheikhzadeh, S M Abtahi, and A Zadhoush, 'A Simple Review of Soil Reinforcement by Using Natural and Synthetic Fibres', Construction and Building Materials 30 (2012), 100-16.

27 E. Ibraim, D. Muir Wood, K. Maeda, and H. Hirabayash, 'Fibre-Reinforce Granular Soils Behaviour: Numerical Approach', Geomechanics and Geotechnics of Particulate Media: Proceedings of the International Symposium on Geomechanics and Geotechnics of Particulate Media, Ube, Japan, 12-14 September (2006), 443-48.

28 M. Labat, C. Magniont, N. Oudhof, and J-E. Aubert, 'From the Experimental Characterization of the Hygrothermal Properties of Straw-Clay Mixtures to the Numerical Assessment of Their Buffering Potential', Building and Environment, 97 (2016), 69-81, http://dx.doi.org/10.1016/i.buildenv.2015.12.004.

29 A. Laborel-Préneron, J-E. Aubert, C. Magniont, and A. Bertron, 'Influence of Straw Content on the Mechanical and Thermal Properties of Bio-Based Earth Composites', in First International Conference on Bio-based Building Materials June 22nd - 24th 2015 (ClermontFerrand, France: 2015).

30 A. Laborel-Préneron, J-E. Aubert, C. Magniont, C. Tribout, and A. Bertron, 'Plant Aggregates and Fibers in Earth Construction Materials: A Review', Construction and building materials, 111 (2016), 719-34, http://dx.doi.org/10.1016/j.conbuildmat.2016.02.119.

31 T. M. Le, and K. L. Pickering, 'The Potential of Harakeke Fibre as Reinforcement in Polymer Matrix Composites Including Modelling of Long Harakeke Fibre Composite Strength', Composites Part A: Applied Science and Manufacturing, 76 (2015), 44-53, http://dx.doi.org/10.1016/i.compositesa.2015.05.005. 
32 C. Li, 'Mechanical Response of Fiber-Reinforced Soil,' (The University of Texas at Austin: http://repositories.lib.utexas.edu/bitstream/handle/2152/1781/lic25697.pdf?sequence=2, 2005).

33 S.M. Luz, A.R. Goncalves, and A.P. Del'Arco Jr., 'Mechanical Behavior and Microstructural Analysis of Sugarcane Bagasse Fibers Reinforced Polypropylene Composites', Composites Part A: Applied Science and Manufacturing, 38 (2007), 1455-61, doi:10.016/j.compositesa.2007.01.014.

34 M. Maalej, V. C. Li, and T. Hashida, 'Effect of Fiber Rupture on Tensile Properties of Short Fiber Composite', Journal of Engineering Mechanics, 121 (1995), 903-13.

35 K. Maeda, and E. Ibraim, 'Dem Analysis of 2d Fibre-Reinforced Granular Soils. ', in Proceedings of the International Symposium on Deformation Characteristic of Geomaterials (IS-Atlanta 2008), pp. 623-28.

36 Y. Millogo, J.-C. Morel, J.-E. Aubert, and K. Ghavami, 'Experimental Analysis of Pressed Adobe Blocks Reinforced with Hibiscus Cannabinus Fibers', Construction and Building Materials, 52 (2014), 71-78.

37 E. Obonyo, D. Tate, V. Sika, and M. Tia, 'Advancing the Structural Use of Earth-Based Bricks: Addressing Key Challenges in the East African Context', Sustainability, 2 (2010), 3561-71, doi:10.390/su2113561.

38 C. Rivera-Gómez, C. Galán-Marín, and F. Bradley, 'Analysis of the Influence of the Fiber Type in Polymer Matrix/Fiber Bond Using Natural Organic Polymer Stabilizer', Polymers, 6 (2014), 977-94; doi:10.3390/polym6040977.

39 V. Sharma, B. M. Marwaha, and H. K. Vinayak, 'Enhancing Durability of Adobe by Natural Reinforcement for Propagating Sustainable Mud Housing', International Journal of Sustainable Built Environment, 5 (2016), 141-55, http://dx.doi.org/10.1016/j.ijsbe.2016.03.004.

40 A. Slosarczyk, 'The Influence of Non-Metallic and Metallic Fibres on the Mechanical Properties of Cement Mortars', in International Symposium on Brittle Matrix Composite 10, ed. by J. Olek A. M. Brandt, M. A. Glinicki, C. K. Y. Leung (Warsaw: Woodhead Publishing, 2012).

41 J. Smith, and S. Bhatia, 'Natural Fibers Raise Social Issues', Materials Today 8(2005), 72-81, doi:10.1016/S369-7021(05)71193-7.

42 A. Subrianto, T. Lecompte, A. Perrot, A. Le Duigou, and G. Ausias, 'A Novel Pull-out Device Used to Study the Influence of Pressure During Processing of Cement-Based Material Reinforced with Coir', in 1st International Conference on Bio-based Building Materials. June 22nd - 24th. (Clermont-Ferrand, France.: 2015).

43 T. Sunny, and A. Joy, ' Study on the Effects of Marine Clay Stabilized with Banana Fibre', International Journal of Scientific Engineering and Research, 4 (2016), 96-98.

44 C. S. Tang, B. Shi, and L. Z. Zhao, 'Interfacial Shea Strength of Fiber Reinforced Soil', Geotextiles and Geomembranes, 28 (2010), 54-62, doi:10.1016/j.geotexmem.2009.10.001

45 M. Tuyan, and H. Yazıcı, 'Pull-out Behavior of Single Steel Fiber from Sifcon Matrix', Construction and Building Materials 35 (2012), 571-77, doi:10.1016/j.conbuildmat.2012.04.110.

46 Q. Wang, R. Tang, Q. Cheng, X. Wang, and F. Liu, 'Research on Static Triaxial Mechanical Properties of New Cementsoil Reinforced with Polypropylene Fiber', Advances in Materials Science and Engineering, 2014 (2014), 1-10, http://dx.doi.org/10.1155/2014/532327.

47 P. P. Yalley, Use of Waste and Low Energy Materials in Construction (Germany: LAP LAMBERT Academic Publishing, 2012).

48 J. Zhu, H. Zhu, J. Njuguna, and H. Abhyankar, 'Recent Development of Flax Fibres and Their Reinforced Composites Based on Different Polymeric Matrices', Materials, 6 (2013), 5171-98; doi:10.3390/ma6115171 


\section{Tables}

Table 1: Properties of the experimental soil

\begin{tabular}{lc}
\hline Properties & Value \\
\hline Proctor test & \\
$\quad$ Optimum moisture content $(\%)$ & 11.8 \\
$\quad$ Maximum dry density $\left(\mathrm{Mg} / \mathrm{m}^{3}\right)$ & 1.83 \\
Atterberg limits & \\
$\quad$ Liquid limit (\%) & 18.0 \\
$\quad$ Plastic limit (\%) & 31.7 \\
$\quad$ Plasticity index (\%) & 13.7 \\
Soil classification & \\
$\quad$ USCS & $\mathrm{CL}$ \\
Particle size distribution & \\
$\quad$ Gravel $(>2 \mathrm{~mm})(\%)$ & 8 \\
$\quad$ Sand $(2-0.063 \mathrm{~mm})(\%)$ & 64 \\
$\quad$ Silt $(0.063-0.002 \mathrm{~mm})(\%)$ & 16 \\
$\quad$ Clay $(<0.002 \mathrm{~mm})(\%)$ & 12 \\
pH $\quad$ & 6.67 \\
$\quad$ value &
\end{tabular}

Table 2: Chemical element/composition of experimental soil

\begin{tabular}{lc}
\hline $\begin{array}{l}\text { Element/ } \\
\text { compound }\end{array}$ & Concentration $(\mathrm{mg} / \mathrm{l})$ \\
\hline $\mathrm{Al}^{3+}$ & 2.84 \\
$\mathrm{Ca}^{2+}$ & 5.68 \\
$\mathrm{SiO}_{2}$ & 76.62 \\
$\mathrm{~K}$ & 2.40 \\
$\mathrm{Zn}$ & 0.31 \\
$\mathrm{~Pb}$ & 4.47 \\
$\mathrm{Fe}^{2+}$ & 2.36 \\
$\mathrm{Mg}^{2+}$ & 10.50 \\
$\mathrm{Cl}^{-}$ & 9.00 \\
$\mathrm{PO}_{4}{ }^{3-}$ & 0.15 \\
$\mathrm{SO}_{4}{ }^{2-}$ & 3.00 \\
\hline
\end{tabular}

Table 3: Properties of experimental fibres

\begin{tabular}{lcccc}
\hline Fibre type & \multicolumn{3}{c}{ Property } \\
\cline { 2 - 5 } & $\begin{array}{c}\text { Diameter } \\
(\mathrm{mm})\end{array}$ & $\begin{array}{c}\text { Tensile strength } \\
(\mathrm{MPa})\end{array}$ & $\begin{array}{c}\text { Modulus of } \\
\text { elasticity }(\mathrm{GPa})\end{array}$ & $\begin{array}{c}\text { Water absorption } \\
(\%)\end{array}$ \\
\hline Bagasse & $0.31-1.19$ & $25-62$ & $0.5-1.3$ & $153-219$ \\
Coconut & $0.18-1.01$ & $83-222$ & $2.3-2.8$ & $145-209$ \\
Oil Palm & $0.19-0.82$ & $65-141$ & $0.7-1.1$ & $54-103$ \\
\hline
\end{tabular}


Table 4: Fibre diameter and length used for pull-out test

\begin{tabular}{lcccccc}
\hline Fibre type & Mean diameter \pm & Mean length \pm SD & \multicolumn{4}{c}{ Length embedded in soil matrix $(\mathrm{mm})$} \\
\cline { 4 - 6 } & $\mathrm{SD}(\mathrm{mm})$ & $(\mathrm{mm})$ & $1 / 2$ & $1 / 4$ & $1 / 8$ & $1 / 16$ \\
\hline Bagasse & $0.78 \pm 0.19$ & $110 \pm 28.93$ & 55 & 28 & 14 & 7 \\
Coconut & $0.40 \pm 0.17$ & $103 \pm 17.94$ & 52 & 26 & 13 & 6 \\
Oil palm & $0.38 \pm 0.08$ & $38 \pm 5.84$ & 19 & 10 & 5 & 3 \\
\hline
\end{tabular}

One hundred fibres (from each fibre type) were randomly selected for determining the length and diameter as described in Danso et al. ${ }^{17}$

Table 5: Gaps in fibre-soil matrix and difference b/t dry and wet fibre diameters

\begin{tabular}{lccc}
\hline Difference & \multicolumn{3}{c}{ Fibre diameter $(\mathrm{mm})$} \\
\cline { 2 - 4 } & Bagasse & Coconut & Oil palm \\
\cline { 2 - 4 } & Mean \pm SD & Mean \pm SD & Mean \pm SD \\
\hline Gap b/t fibre and soil matrix (mm) & $0.018 \pm 0.009$ & $0.077 \pm 0.022$ & $0.038 \pm 0.006$ \\
Saturated fibre diameter (mm) & $0.794 \pm 0.209$ & $0.623 \pm 0.227$ & $0.403 \pm 0.132$ \\
Dry fibre diameter (mm) & $0.769 \pm 0.204$ & $0.529 \pm 0.211$ & $0.352 \pm 0.128$ \\
Shrinkage (dif. b/t saturated and dry fibre & $0.025 \pm 0.009$ & $0.094 \pm 0.023$ & $0.051 \pm 0.007$ \\
diameter (mm)) & & & \\
Ratio of gap to shrinkage & $0.720 \pm-$ & $0.819 \pm-$ & $0.745 \pm$ \\
\hline
\end{tabular}

Table 6: Pull-out test results of fibre-soil composite (Fraction indicates fibres pulled out over test replicates)

\begin{tabular}{lcccccccccccc}
\hline Fibre & \multicolumn{10}{c}{ Length of fibre embedded in soil (mm) } \\
\cline { 2 - 12 } & 55 & 28 & 14 & 7 & 52 & 26 & 13 & 6 & 19 & 10 & 5 & 3 \\
\hline Bagasse & $0 / 3$ & $0 / 3$ & $0 / 3$ & $3 / 3$ & & & & & & & & \\
Coconut & & & & & $0 / 3$ & $0 / 3$ & $2 / 3$ & $3 / 3$ & & & & \\
Oil Palm & & & & & & & & $0 / 3$ & $0 / 3$ & $0 / 3$ & $3 / 3$ \\
\hline
\end{tabular}




\section{Figures}

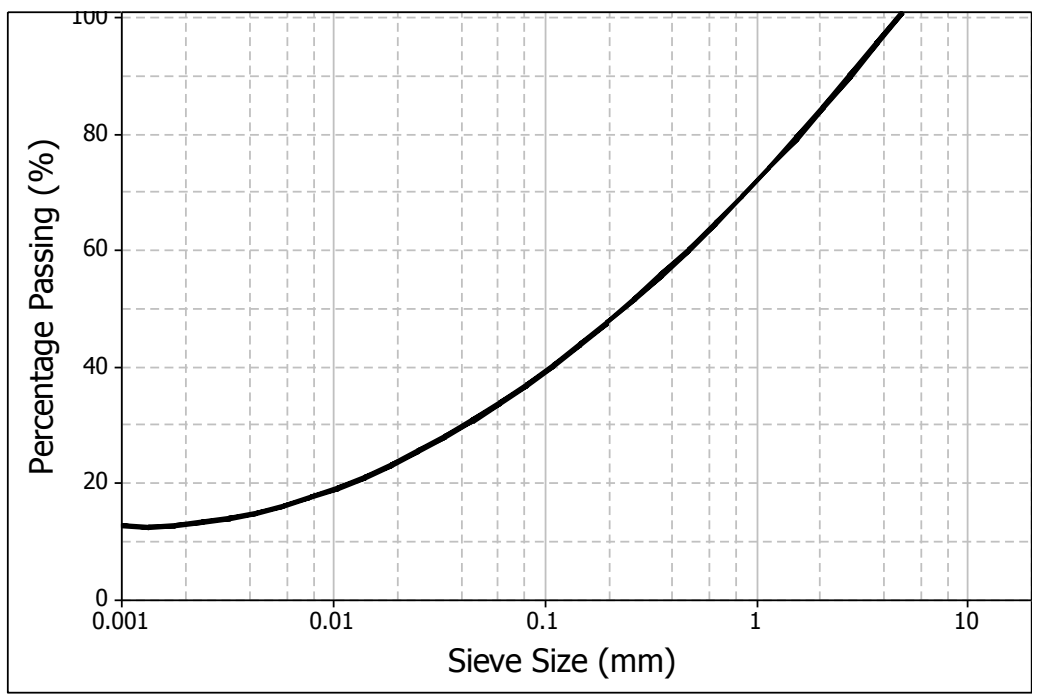

Fig. 1: Particle size distribution of the experimental soil
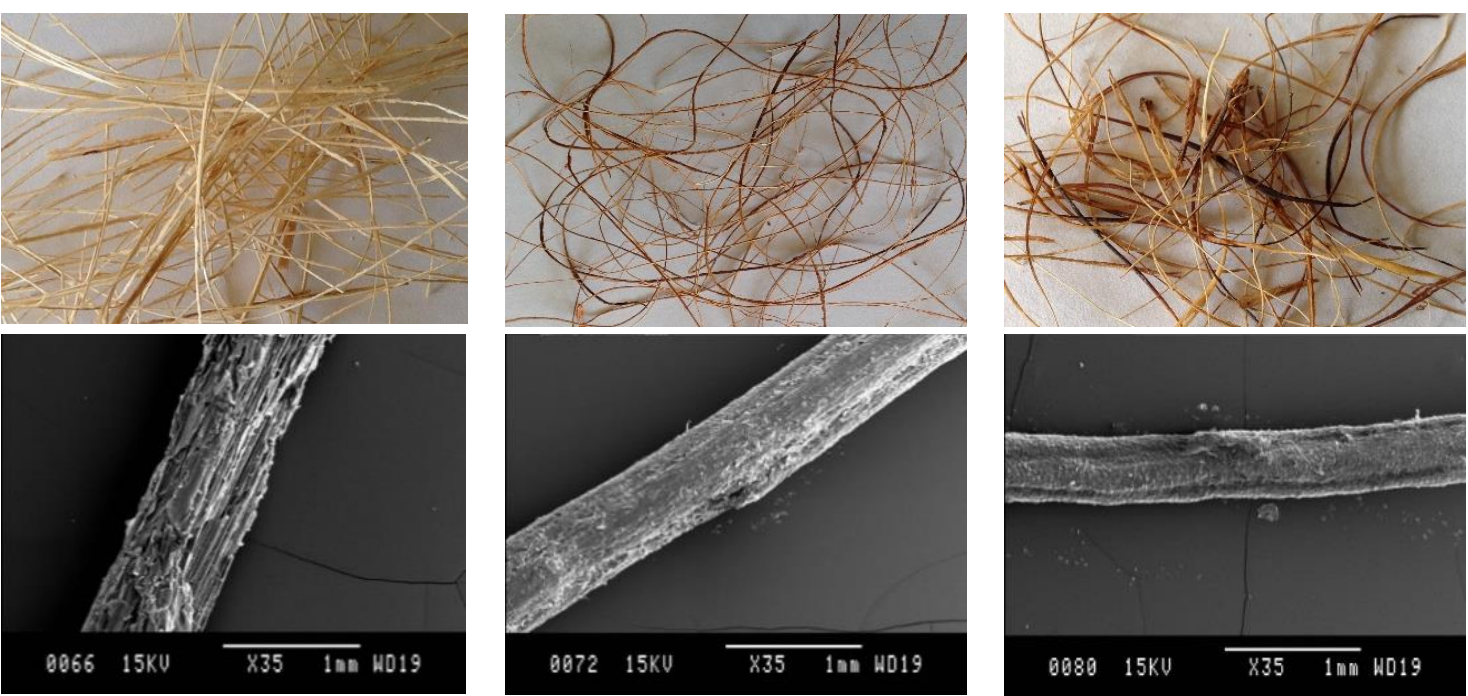

Bagasse fibre

Coconut fibre

Oil palm fibre

Fig. 2: Photographs and SEM micrographs of the fibre types 


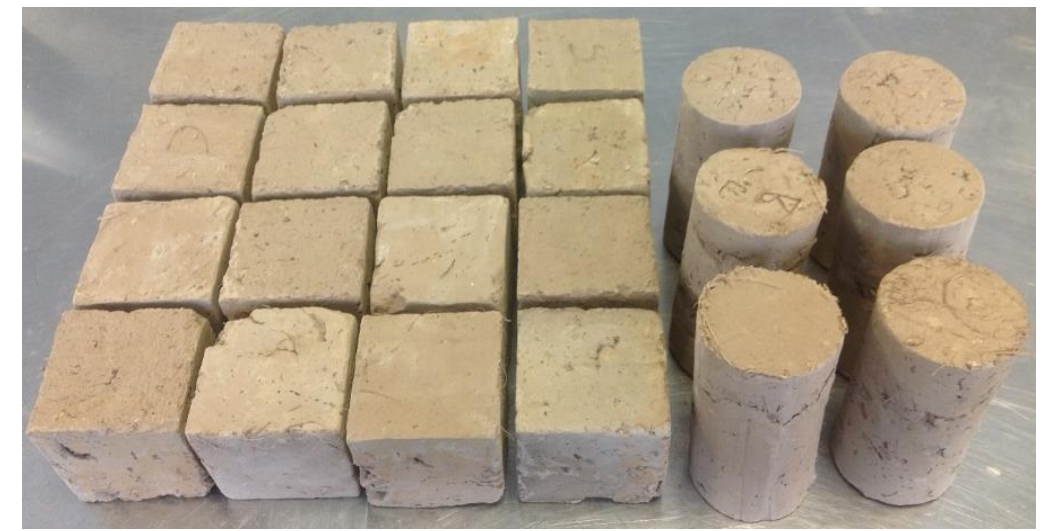

Fig. 3: Cube and Cylindrical Specimen

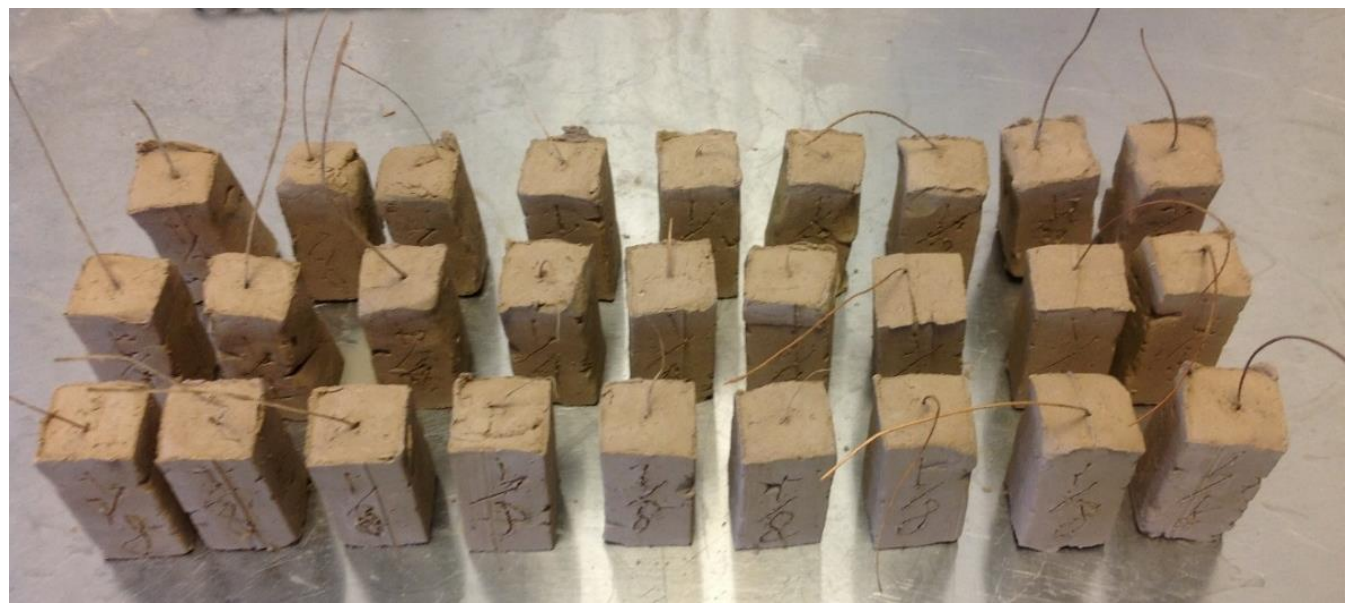

Fig. 4: Drying samples for pull-out test
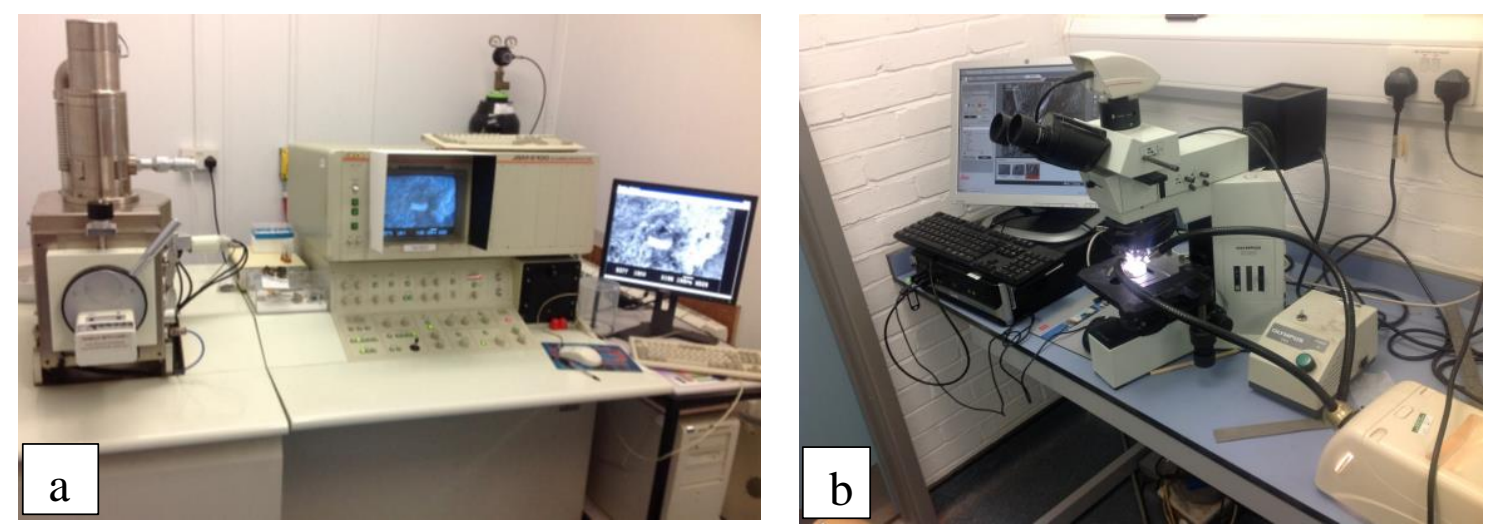

Fig. 5: Analysing Specimens for Gaps with (a) JSM-6100 Scanning Microscope, (b) OLYMPUS BX40 Computerised Optical Microscope 


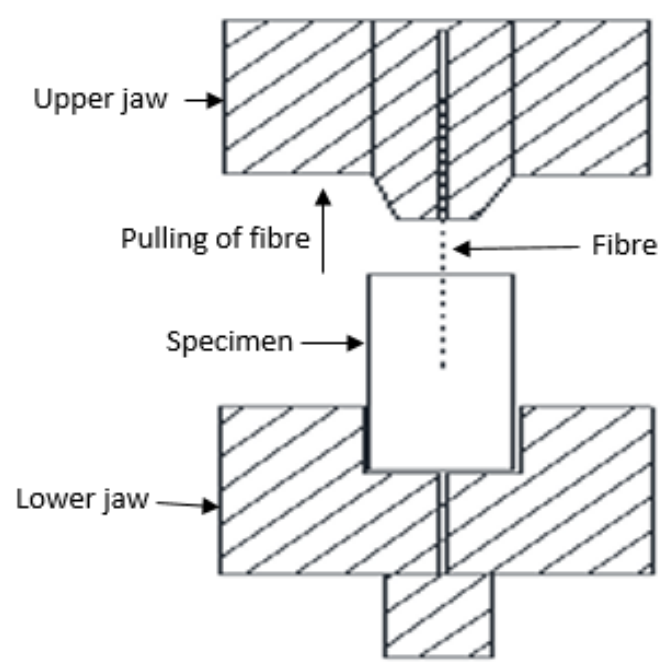

Schematic diagram

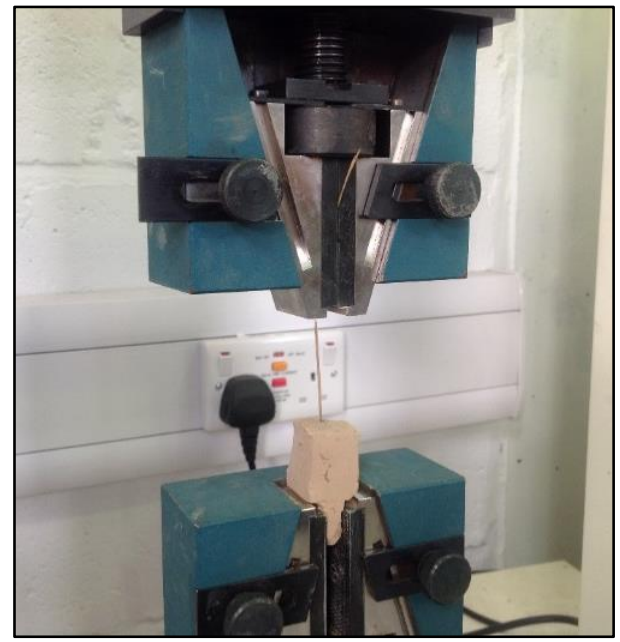

Laboratory photo

Fig. 6: Pull-Out Test Setup

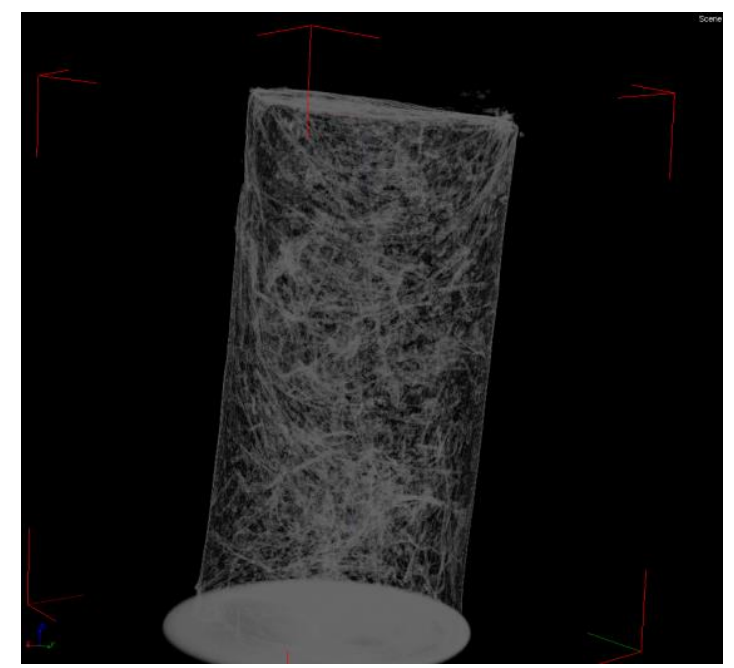

Full 3D view

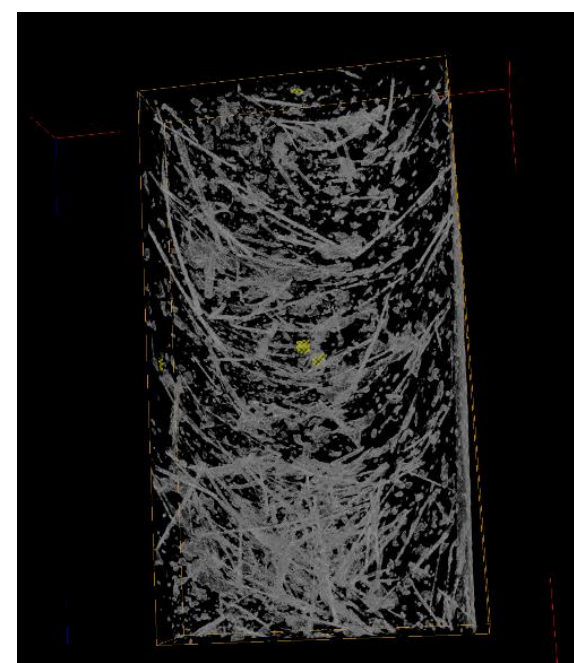

Sliced internal 2D view

Fig. 7: Image from Modelled CT scan Slices The grey curved lines show the fibres 

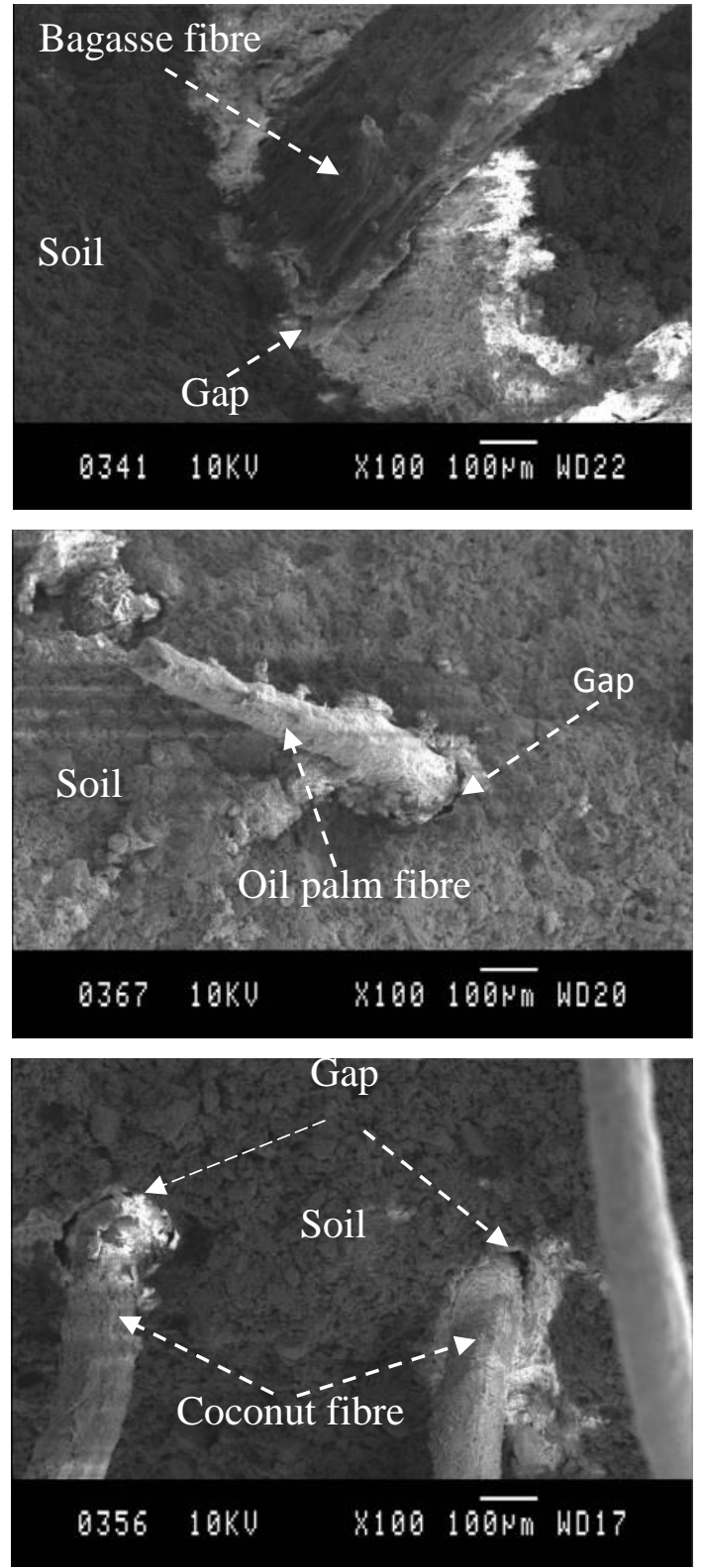

Fig. 8: SEM micrographs showing gaps between fibre and soil matrix 

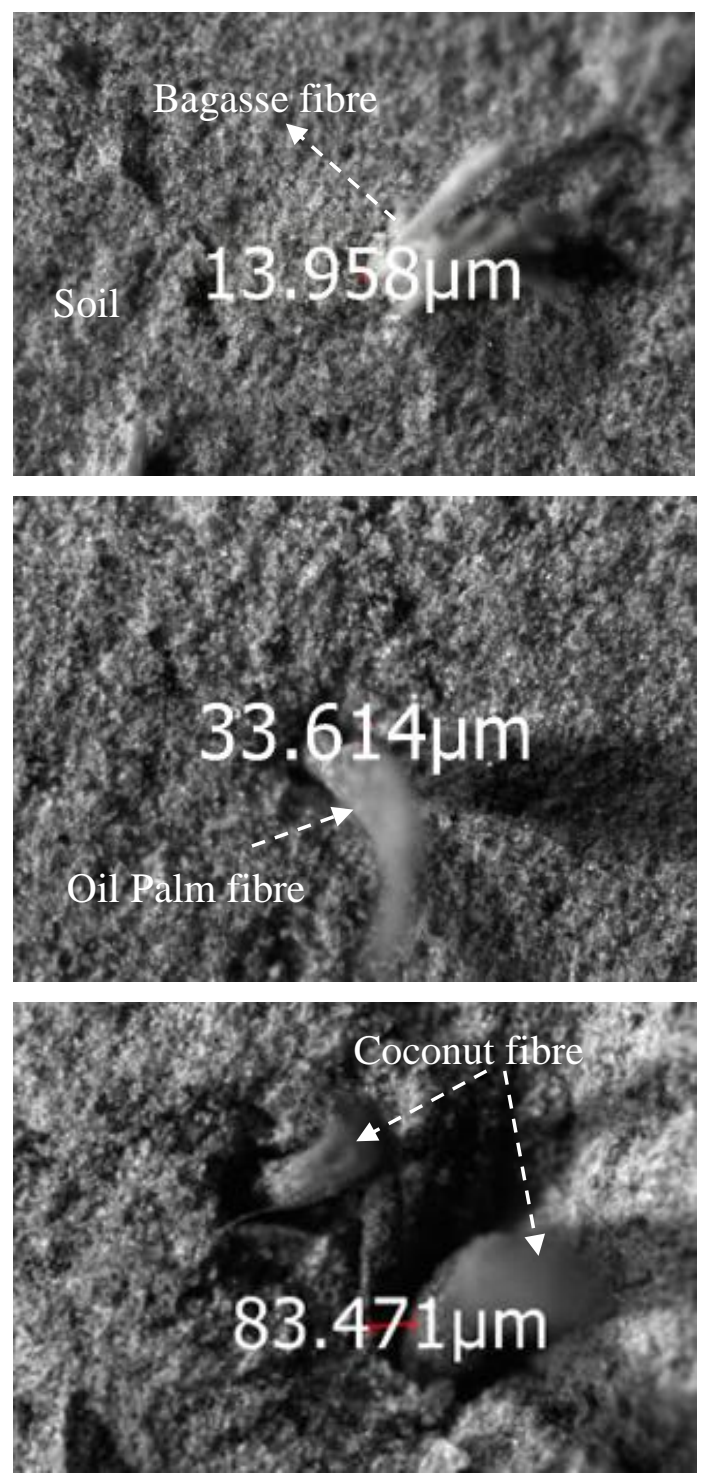

Fig. 9: Optical microscope micrographs showing measured gaps between fibres and soil matrix
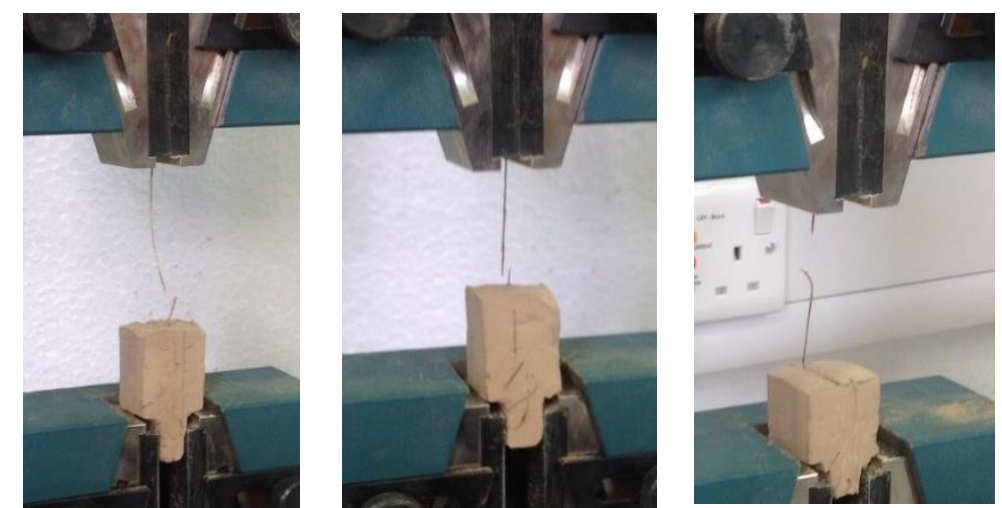

Fig. 10: Fibres failure under pull-out test 